\title{
Defendiendo territorio y dignidad
}

Los conflictos en defensa del territorio se están multiplicando en México, no sólo en el campo, por parte de comunidades indígenas o rurales, sino también en las ciudades y zonas metropolitanas. La explotación de los recursos naturales, la urbanización, las viejas y nuevas formas de extracción y producción de energía para alimentar el sistema productivo y el estilo de vida actual están generando un ecocidio que centenares de colectivos y comunidades están haciendo visible $\mathrm{y}$ al que intentan resistir como pueden.

Estas resistencias, aunque no estén luchando contra el mismo problema, se parecen y se caracterizan, entre otras cosas, por falta de información y diálogo con los habitantes de las zonas afectadas; falta de respecto, abuso de poder y engaño por parte de las autoridades; existencia de intereses y beneficios que no se reparten en las comunidades; impactos a la salud de los habitantes de los territorios afectados; reubicaciones forzosas; pérdida de biodiversidad, tierra o recursos naturales que garantizaban el sustento de la comunidad; así como pérdida de estilo y calidad de vida.

Estas resistencias también se parecen, por un lado, porque los proyectos de muerte, como los sujetos de estas luchas los definen, y los esfuerzos para contra-

Alice Poma (2017). Defendiendo territorio y dignidad. Emociones y cambio cultural en luchas contra represas en España y México. Campina Grande: EDUEPB, Red WATERLATGOBACIT, Escuela de Estudios Hispanoamericanos (CSIC). 
rrestarlos producen, entre otras cosas, dolor, sufrimiento, agobio, ansiedad, incertidumbre, miedo, rabia, coraje, impotencia e indignación, y, por otro lado, porque generan también dignidad y esperanza, hermanando a los que luchan y fortaleciendo vínculos personales y tejidos sociales.

Si bien todos los que han participado en estas experiencias han sentido en su propia carne y han tenido que convivir y aprender a manejar la intensidad emocional que acompaña estas resistencias, aún son escasos en México los análisis académicos que permiten comprender el papel de las emociones en estas luchas.

El libro Defendiendo territorio y dignidad. Emociones y cambio cultural en luchas contra represas en España $y$ México representa un esfuerzo para colmar esta laguna, presentando los resultados de una investigación que da luz sobre el papel de las emociones en tres resistencias contra presas y el cambio que experimentaron los sujetos que resistieron.

Los casos que analiza la autora son la lucha por la defensa de Riaño (León, Castilla y León), el conflicto por la defensa de río Grande (Málaga, Andalucía, España) y la lucha contra la presa de San Nicolás (en la región conocida como los Altos de Jalisco, en México). Los casos presentados son muy interesantes en tanto se distinguen, primero, por una diferencia de temporalidad: la defensa de río Grande ocurrió entre 2006 y 2007, la lucha contra la presa de San Nicolás entre 2004 y 2005, y el caso de Riaño entre 1986 y 1987, después de la dictadura franquista. En segundo lugar, se distinguen por el resultado de las luchas: la desestimación de los proyectos para los casos de Málaga y de los Altos de Jalisco, y la muy triste inundación de los ocho pueblos del Valle de Riaño. Sin duda, estas diferencias permiten a la autora construir un entramado analítico original en el cual se pueden apreciar procesos comunes entre los distintos casos a pesar del lugar, tiempo y resultado final de la lucha. 
A partir de un acercamiento a la literatura sobre conflictos contra presas y, más en general, sobre conflictos socioambientales y la observación de estas resistencias, la autora construyó las preguntas y el enfoque de la investigación que la llevaron a

explorar la experiencia cotidiana, menos visible, de la defensa del territorio, bajo la intuición de que allí se podía encontrar alguna respuesta a preguntas tan importantes como ¿qué es lo que mueve a la gente a defender su territorio? ¿qué implica defender un territorio amenazado? ¿qué impacto tiene la experiencia de lucha en la vida de los sujetos? (p.22).

Una parte importante del libro -el segundo capítulo- es dedicada al papel de las emociones en la protesta y en el cambio cultural que viven los sujetos que defienden el territorio. La autora nos ofrece una explicación concisa y rigurosa de las emociones como constructos socioculturales, presentando al lector diferentes tipologías de emociones, así como conceptos extrapolados de la literatura que permiten comprender diferentes dinámicas de estas resistencias, desde las emociones colectivas hasta la energía emocional que se produce en los momentos colectivos y en las pequeñas victorias.

Muy interesante para el estudio de los conflictos socioambientales resulta el armazón teórico de la investigación, constituido por conceptos extraídos de la literatura anglosajona, principalmente sociológica, especializada en analizar las emociones en la protesta desde un enfoque desde abajo surgido a su vez de una literatura crítica donde coinciden autores de diferentes geografías y culturas académicas. El resultado es un hábil uso de los conceptos como herramientas analíticas utilizadas con el fin de comprender el papel de las emociones en las resistencias analizadas y en el cambio que vivieron los sujetos que protagonizaron estas resistencias. 
En la segunda parte del libro, la autora nos presenta brevemente los casos de estudio. En esta parte, en lugar de describir minuciosamente cada una de las luchas, se ha optado por una comparación de los tres casos de estudio que evidencia algunos aspectos considerados más relevantes para el análisis posterior. Sin embargo, donde más se aprecia la riqueza del trabajo etnográfico y el potencial del enfoque es en el análisis de las tres experiencias.

El análisis de las diferentes tipologías de emociones permite comprender la complejidad de la dimensión emocional y su papel en las experiencias de resistencias. El trabajo, pionero en la producción científica de habla española, muestra de manera sistematizada cómo son los vínculos afectivos, tanto entre actores de los conflictos como entre estos y el territorio. De hecho, analizando el apego al lugar, la autora muestra cómo la pérdida del lugar querido es una dinámica psicológica comparable al luto de un familiar que, además, comporta la disolución de las relaciones sociales de las comunidades afectadas. Las emociones que acompañan la noticia de la construcción de una presa influyen así en la reelaboración de la realidad por parte de los afectados. A estas emociones, que la autora define, apoyándose a otro trabajo, como del trauma, se suman las emociones de la resistencia que generan los beneficios de la protesta, entre los que destacan la dignidad, la unión y el empoderamiento.

El análisis de las tres resistencias muestra también cómo los estados de ánimo pueden influir en la dinámica de la protesta, favoreciendo o desfavoreciendo la movilización.

Otra tipología de emociones que se trata en este trabajo es el de las emociones morales. Estas dependen de los valores subyacentes en los sujetos, influyen en el proceso de reelaboración de la situación como injusta, y cuando son compartidas fortalecen la identificación colectiva pues presuponen no sólo un sentir común, sino también valores comunes. A lo largo del libro, pues, se muestra cómo el 
compartir indignación, ultraje, orgullo, formas complejas de rabia, miedo, disgusto, entre otras, une y hermana a los sujetos, que no sólo defienden sus territorios de la construcción de la presa, sino su dignidad, amenazada.

En el análisis del cambio que experimentan los habitantes que resisten a la construcción de las presas en los tres territorios, se presenta el resultado de procesos emocionalcognitivos que son tanto individuales como colectivos, que motivan y animan la protesta y fortalecen la participación, influyendo en la elaboración de nuevos valores, ideas, creencias e imaginarios que pueden manifestarse en nuevas prácticas cotidianas.

La investigación muestra que algunos procesos emocionalcognitivos que han sido seleccionados para poder analizar el cambio hacen que algunos valores subyacentes vuelvan a la superficie, permitiendo a los sujetos reelaborar la realidad que están viviendo. Este proceso es presentado en el libro como un reautoaprendizaje, y ha sido puesto en evidencia gracias al enfoque microsociológico. La trascendencia de centrar el análisis en la experiencia de los habitantes que se auto-organizaron ha permitido mostrar cómo las resistencias analizadas representaron un momento de ruptura en la vida de los habitantes de los territorios amenazados por las presas, que se tradujo también en una reelaboración de la idea de democracia y progreso, así como en el surgimiento de nuevas prácticas y experiencias, como la creación de nuevas asociaciones que trabajan en el territorio, o el empoderamiento de los sujetos tanto personal como político.

A modo de conclusión, el libro que se presenta en esta reseña es un ejemplo de cómo la aplicación de una línea de investigación aún poco explorada en nuestro país puede agregar elementos relevantes para la comprensión de los conflictos socioambientales.

Este trabajo abre así nuevos horizontes en el campo de la investigación social y pone en evidencia la necesidad 
de estudios que produzcan conocimientos que puedan no sólo contribuir a la excelencia académica a nivel internacional, sino también estimular un dialogo y un proceso de autorreflexión con los sujetos sociales a partir de su propia experiencia.

Hay que destacar que, gracias a la colaboración de las tres casas editoras, el libro está también disponible en su versión digital de forma gratuita (http://waterlat.org/GeneralPDFs/ Pomaweb.pdf), aspecto que apreciarán los investigadores y los estudiantes que estén interesados en las complejas interrelaciones entre las dimensiones sociopolítica y ambiental que tienen lugar en los procesos de lucha que llevan a cabo las comunidades humanas que deciden resistir los impactos negativos de las grandes obras de infraestructura hidráulica, una problemática, sin sombra de duda, de carácter global. 